\title{
Rod-Shaped Magnetite Nano/Microparticles Synthesis at Ambient Temperature
}

\author{
Balaprasad Ankamwar and Ashwini Thorat \\ Department of Chemistry, University of Pune, Ganeshkhind, Pune 411007, India \\ Correspondence should be addressed to Balaprasad Ankamwar; bankamwar@yahoo.com
}

Received 5 June 2012; Revised 24 July 2012; Accepted 8 August 2012

Academic Editor: Ioannis Kourkoutas

Copyright (c) 2013 B. Ankamwar and A. Thorat. This is an open access article distributed under the Creative Commons Attribution License, which permits unrestricted use, distribution, and reproduction in any medium, provided the original work is properly cited.

\begin{abstract}
Here, we reported room temperature synthesis of $\mathrm{Fe}_{3} \mathrm{O}_{4}$ rod-shaped nano/microparticles by chemical reduction method from $\mathrm{FeCl} \mathrm{C}_{3}$ precursor and $\mathrm{NaBH}_{4}$ as the reducing agent in the presence of the pyrrole as a capping agent. The magnetic $\mathrm{Fe}_{3} \mathrm{O}_{4}$ particles were characterized by several methods, such as SEM, XRD, FTIR, and TGA. The average aspect ratio of $\mathrm{Fe}_{3} \mathrm{O}_{4}$ rod-shaped particles was $\sim 2.8$. These particles were redispersed in deionised water to form a colloidal solution and showed magnetic properties. This economical synthesis route is scalable, and $\mathrm{Fe}_{3} \mathrm{O}_{4}$ particles can be exploited for various applications such as MRI contrast enhancement, biodiseperations, Ni-Fe batteries, and as a catalyst.
\end{abstract}

\section{Introduction}

Recently, magnetic nano- and microparticles have become one of the most exciting and rapidly growing areas in material chemistry, separation technology, biology, and biomedicine, leading to a number of potential applications [1]. $\mathrm{Fe}_{3} \mathrm{O}_{4}$ has received major attention, as one of the most important transition magnetic metal oxides due to its extensive applications. It has been considered as an ideal material for magnetic data storage [2], a candidate for biological application such as a tag for sensing and imaging [3], and a drug-delivery carrier for antitumor therapy [4]. Magnetite $\left(\mathrm{Fe}_{3} \mathrm{O}_{4}\right)$ is widely exploited due to its strong magnetic properties as well as extensive applications in biotechnology and medicine [5]. Especially, the $\mathrm{Fe}_{3} \mathrm{O}_{4}$ nano- or microspheres have smooth and large-surface areas which can be used for maximal protein, enzymes, antibodies, and anticancer agents binding [6]. Ferrimagnetic iron oxide microparticles have been typically used for recording materials [7], but these particles are even used as tracers for investigating the behavior of air-borne matter in the human and animal respiratory tract [8] and the mechanical properties of living cells [9]. As they are chemically stable, nontoxic, and noncarcinogenic [10], they permit clearance studies in the human lungs over time periods up to 1 year. Ferromagnetic and Ferrimagnetic particles can be detected in the human body by magnetopneumographic (MPG) methods [11]. Ferrimagnetic particles were also used for measurements of macrophage functions and cellular integrity (viscoelasticity) in vivo and in vitro [9]. $\mathrm{Fe}_{3} \mathrm{O}_{4}$ particles in the micrometer size range can be produced by either a crystallization process [12] or by nebulization of a colloidal solution [13]. Many techniques have been reported in the literature for chemical synthesis of these particles such as the sol-gel [14], microemulsion [15], sonochemical [16], ultrasonic spray pyrolysis [17], and microwave plasma [18]. Each preparation method has its advantages and disadvantages, which primarily relate to particles size distribution, production scale, and cost. Wet chemical processes are capable from the economical perspective but consist of many steps. The gas-phase synthesis process is one-step process with relatively high production rate, but production costs are high. Two important synthesis routes are the thermal decomposition [19] and the chemical reduction [20] methods. A characteristic and serious problem is in assembling and stabilizing magnetic particles as it has high affinity to agglomerate, which is an obstacle to its application for magnetic storage. This barrier can be resolved if the particles are dispersed using proper dispersing agent. Various dispersing agents were reported earlier such as SDS, Triton-X, and PAA; however, this more or less resulted in 
TABLE 1: This shows length, width, and aspect ratio of $\mathrm{Fe}_{3} \mathrm{O}_{4}$ nano/microrods from Figure 1(F).

\begin{tabular}{lcc}
\hline $\begin{array}{l}\text { Length of } \mathrm{Fe}_{3} \mathrm{O}_{4} \text { rods } \\
(\mathrm{nm})\end{array}$ & $\begin{array}{c}\text { Width of } \mathrm{Fe}_{3} \mathrm{O}_{4} \text { rods } \\
(\mathrm{nm})\end{array}$ & Aspect ratio \\
\hline 833.33 & 444.44 & 1.875 \\
1555.55 & 444.44 & 3.500 \\
1444.44 & 333.33 & 4.333 \\
555.55 & 333.33 & 1.666 \\
\hline
\end{tabular}

agglomeration of particles. Here, we attempted to solve this problem by synthesizing $\mathrm{Fe}_{3} \mathrm{O}_{4}$ nano/microparticles using chemical reduction method at ambient temperature using pyrrole as dispersing agent.

\section{Experimental Section}

2.1. Chemical and Reagents. Ferric chloride $\left(\mathrm{FeCl}_{3}, \mathrm{AR}\right.$ grade), sodium borohydride $\left(\mathrm{NaBH}_{4}, \mathrm{AR}\right.$ grade), and pyrrole $\left(\mathrm{C}_{4} \mathrm{H}_{5} \mathrm{~N}\right.$, AR grade) were purchased from RANKEM Chemicals, Mumbai, India and used as received. Conductivity water is used throughout the experimental work. Soap solution and Aqua regia were used to wash the apparatus and MilliQ water to rinse the apparatus.

2.2. Synthesis of $\mathrm{Fe}_{3} \mathrm{O}_{4} \mathrm{Nano} /$ Microparticles. $0.27 \mathrm{gm}$ ferric chloride $\left(\mathrm{FeCl}_{3}\right)$ and $0.55 \mathrm{gm}$ of pyrrole $\left(\mathrm{C}_{4} \mathrm{H}_{5} \mathrm{~N}\right)$ were dissolved in $20 \mathrm{~mL}$ of deionised/conductivity water separately and mixed together (labeled as solution "A"). The colour of the solution changes from yellow to orange. Separately, $0.75 \mathrm{gm}$ of $\mathrm{NaBH}_{4}$ was dissolved in $10 \mathrm{~mL}$ of conductivity water (labeled as solution $\mathrm{B}$ ) followed by addition of solution "B" into "A" under vigorous magnetic stirring. Gradually, with an addition of solution $B$, entire solution becomes dark and eventually turns into completely black.

2.3. Characterization of $\mathrm{Fe}_{3} \mathrm{O}_{4}$ Nano/Microparticles. The characterization study was carried out using Bruker, D8Advance X-ray Diffractometer between $2 \theta$ values $30^{\circ}$ to $70^{\circ}$ with low-angle scan. The thermal analysis of TGA and DTA was obtained at DTG-60H and DSC at DSC-60 instrument. The IR spectrum was obtained with a Shimadzu 8400 spectrophotometer.

\section{Results and Discussion}

The well-dispersed $\mathrm{Fe}_{3} \mathrm{O}_{4}$ particles in water (Figure 1(A)) were collected by external magnet as shown in Figure 1(B) from as-prepared solution (inset of Figure 1(B)). The reaction was accompanied by generation of numerous bubbles. The reaction was supposed to be complete once bubble formation ceased and completed after 24 hours under continuous magnetic stirring [21]. The $\mathrm{pH}$ of the solution was observed to be 9.9. To separate the $\mathrm{Fe}_{3} \mathrm{O}_{4}$ particles, a strong magnet was used as shown in Figures 1(B) and 1(D). The $\mathrm{Fe}_{3} \mathrm{O}_{4}$ particles were then washed, redispersed in conductivity water and dried overnight. To prevent agglomeration of $\mathrm{Fe}_{3} \mathrm{O}_{4}$ particles, dispersing agents were added during synthesis. Several commonly used dispersing agents were evaluated in this work including poly(vinylpyrrolidone), (PVP; average molecular weight 10000), poly(acrylic acid), and sodium dodecyl-benzenesulfonate (SDS, 80\%). These surfactants were resulted in agglomeration. Nevertheless, we obtained $\mathrm{Fe}_{3} \mathrm{O}_{4}$ particles without agglomeration using pyrrole as a surfactant. Other surfactants used such as SDS, Triton-X, and PAA, however, resulted in agglomeration of particles and settled down immediately in the solution. This problem was solved by using pyrrole as a surfactant or dispersing agent. Pyrrole was well coated to the surface of the $\mathrm{Fe}_{3} \mathrm{O}_{4}$ particles [21]. Figures $1(\mathrm{E})$ and $1(\mathrm{~F})$ show SEM images of $\mathrm{Fe}_{3} \mathrm{O}_{4}$ rodlike particles. The plausible mechanism of synthesis is as given on the next page [21].

Chen et al. [22] earlier reported that in this approach, the $\mathrm{Fe}_{3} \mathrm{O}_{4}$ spherical nanoparticles were treated with $\mathrm{FeCl}_{3}$ solution. Because of common ion effect, $\mathrm{Fe}^{3+}$ ions were absorbed onto the surface of $\mathrm{Fe}_{3} \mathrm{O}_{4}$ nanoparticles, and $\mathrm{Fe}_{3} \mathrm{O}_{4}$ particles were then surrounded by positively charged $\left(\mathrm{Fe}^{3+}\right)$ shells to prevent their aggregation. This scheme does support our formation processes of pyrrole-coated rod-shaped $\mathrm{Fe}_{3} \mathrm{O}_{4}$ nano/microparticles as shown in Figure 2. Moreover, in this scheme [22], the formed $\mathrm{Fe}^{3+}$ ion shell was also served as the oxidant to polymerize pyrrole monomers which may lead to rod formation over the template of polymer. One more supportive model to prevent the aggregation of nanoparticles has also been proposed by Zhao and Nan [23]. As per their paper, the steric stabilization effect arises from the fact that polymers coating on the surface of particles occupy a certain amount of space. Thus, the space becomes compressed when nanoparticles are brought too close together. An associated repulsive force makes separate nanoparticles from each other and restrains the aggregation of nanoparticles.

The length and width of $\mathrm{Fe}_{3} \mathrm{O}_{4}$ particles were observed in the range between $555.55 \mathrm{~nm}$ and $1555.55 \mathrm{~nm} ; 333.33 \mathrm{~nm}$ and $444.44 \mathrm{~nm}$, respectively. The average aspect ratio that is, length divided by width, was found to be $\sim 2.8$ (Table 1 ).

Figure 3(a), spectrum 1 represents the spectra of the surfactant or dispersing agent, that is, pyrrole. Pyrrole contains secondary amine which shows characteristic peak at $3500-3300 \mathrm{~cm}^{-1}$ due to $\mathrm{N}-\mathrm{H}$ stretching vibrations. Spectrum 2 represents the spectra of the as-prepared $\mathrm{Fe}_{3} \mathrm{O}_{4}$ particles. In this spectra, the wavelength is shifted, that is, 3432 to $3001 \mathrm{~cm}^{-1}$; it shows broad peak due to the coating of cationic surfactant, (pyrrole) which indicates the presence of surfactant that is, pyrrole coated on the surface of $\mathrm{Fe}_{3} \mathrm{O}_{4}$ particles. These wavelengths are shifted due to the attachment of secondary amine. The nitrogen group is attached to the carbon which is having lone pair of electrons. The peak at $1040 \mathrm{~cm}^{-1}$ shows that carbon is attached to nitrogen atom [24]. Spectrum 3 represents the spectra of the $\mathrm{Fe}_{3} \mathrm{O}_{4}$ particles after thermal analysis. Due to the decomposition of pyrrole and possible phase transition of iron, the wavelength was changed. On TGA analysis of a sample, removal of the water molecule and other impurities from $\mathrm{Fe}_{3} \mathrm{O}_{4}$ nano/microparticles takes place. The removal of impurities is exhibited by the weak bands at wavelengths 3186 to 

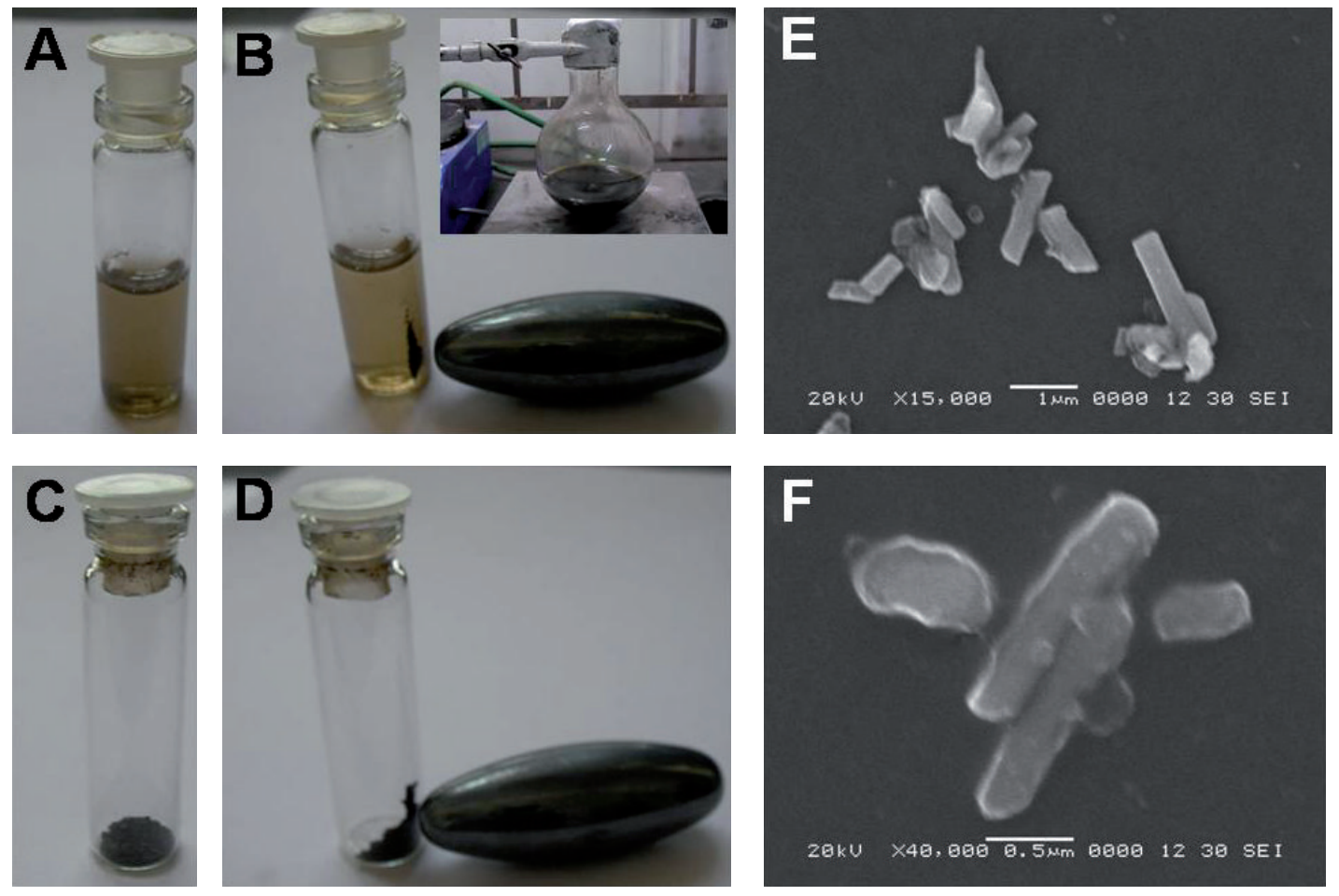

FIGURE 1: In (A) and (C) are represented the colloidal solution and calcinated powder of $\mathrm{Fe}_{3} \mathrm{O}_{4}$ particles, exhibiting their magnetic properties using external magnet (B) and (D), respectively. In (E) is represented lower magnification and in (F) higher magnification SEM image of $\mathrm{Fe}_{3} \mathrm{O}_{4}$ particles.

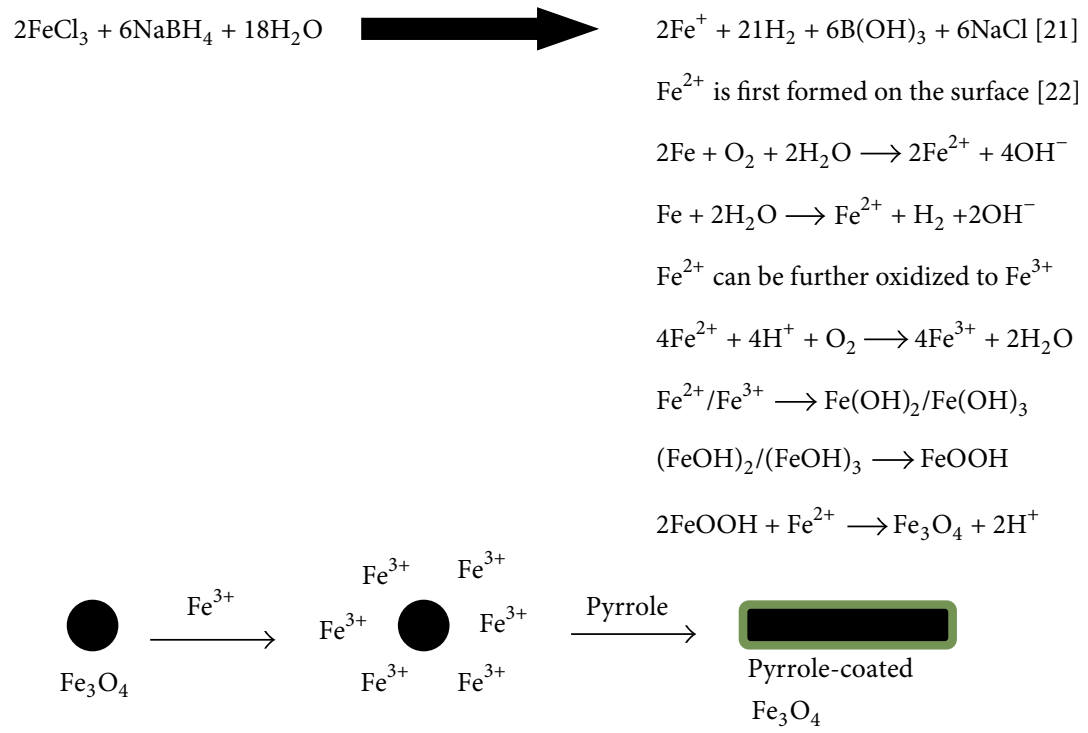

FIgURE 2: Schematic diagram of the formation processes of pyrrole-coated rod-shaped $\mathrm{Fe}_{3} \mathrm{O}_{4}$ nano/microparticles. 


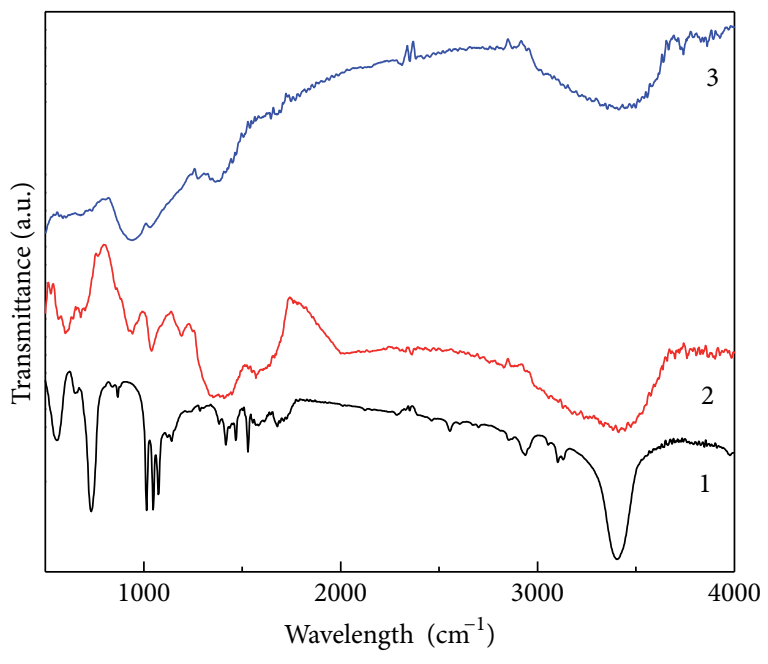

(a)

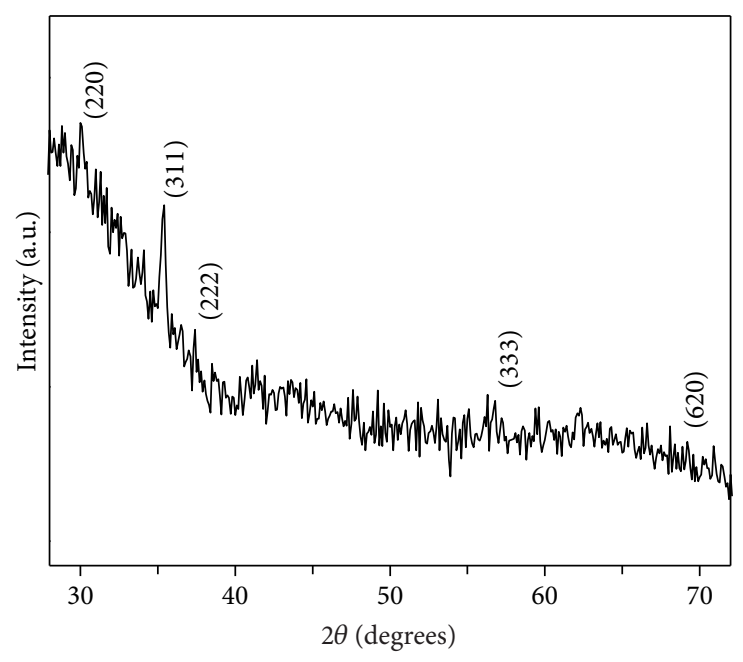

(b)

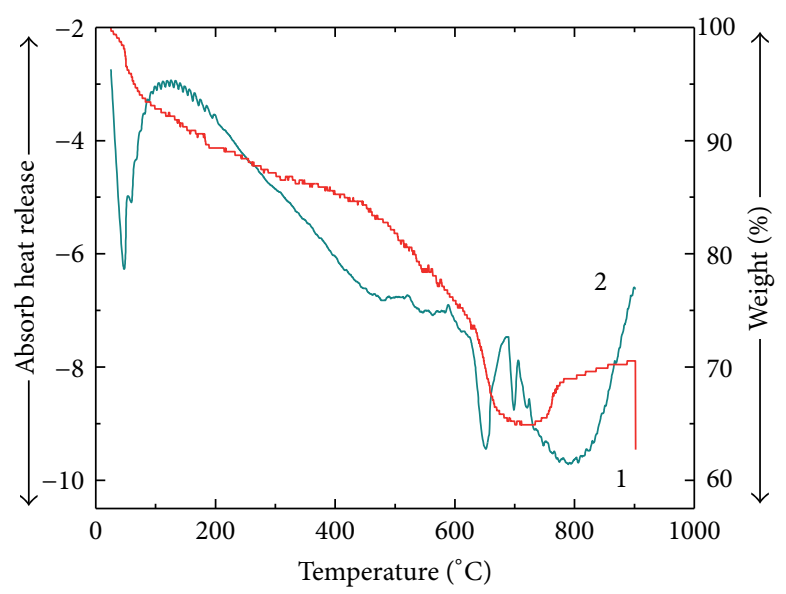

(c)

FIgURE 3: In (a) are represented FTIR spectra of cationic surfactant pyrrole (spectrum 1), as-prepared $\mathrm{Fe}_{3} \mathrm{O}_{4}$ particles (spectrum 2), and $\mathrm{Fe}_{3} \mathrm{O}_{4}$ particles after thermal analysis (spectrum 3); (b) XRD of $\mathrm{Fe}_{3} \mathrm{O}_{4}$ micro/nanoparticles after calcinations; (c) thermogravimetric analysis; (1) differential thermogram analysis (2) patterns of $\mathrm{Fe}_{3} \mathrm{O}_{4}$ particles.

$3498 \mathrm{~cm}^{-1}$ as a result of the shift in a wavelength [25]. At wavelengths 1341, 1365 and $1467 \mathrm{~cm}^{-1}$, C-H stretching was observed due to methyl group. The peaks at 1547 and $1464 \mathrm{~cm}^{-1}$ can be assigned to $\mathrm{C}=\mathrm{C}$ and $\mathrm{C}-\mathrm{N}$ stretching vibrations, respectively. The peaks at 1182 and $901 \mathrm{~cm}^{-1}$ indicate the $\mathrm{C}-\mathrm{H}$ in-plane bending and ring deformation, respectively. The peaks observed at 457 to $430 \mathrm{~cm}^{-1}$ are the characteristic peaks of Fe-O stretching vibrations [26]. Similar patterns were also observed in pyrrole-Fe $[\mathrm{OH}]$ microcomposites. The obvious spectral differences between pure pyrrole and the composites indicate that pyrrole exhibits a different chain structure, and there are physical interactions between particles and pyrrole. The presence of $\mathrm{Fe}_{3} \mathrm{O}_{4}$ particles was strongly supported by a new peak at $588 \mathrm{~cm}^{-1}$ [26]. Figure 3(b) shows the X-ray diffraction pattern (XRD) of $\mathrm{Fe}_{3} \mathrm{O}_{4}$ particles after calcinations under nitrogen atmosphere. The $2 \theta$ values of the standard $\mathrm{Fe}_{3} \mathrm{O}_{4}$ particles were $30.18^{\circ}$, $35.68^{\circ}$, and $37.28^{\circ}$ which correspond to the Bragg reflections
TABLE 2: Observed and standard $2 \theta$ values of $\mathrm{Fe}_{3} \mathrm{O}_{4}$ particles with respective (hkl) planes.

\begin{tabular}{lcc}
\hline Observed $2 \theta$ values & Standard $2 \theta$ Values & Respective (hkl) planes \\
\hline $30.0^{\circ}$ & $30.087^{\circ}$ & $(220)$ \\
$35.4^{\circ}$ & $35.439^{\circ}$ & $(311)$ \\
$37.4^{\circ}$ & $37.071^{\circ}$ & $(222)$ \\
\hline
\end{tabular}

(220), (311), and (222), respectively, (PDF no. 79-0418 of $\mathrm{Fe}_{3} \mathrm{O}_{4}$, wavelength $\left.=1.54060\right)$, whereas the $2 \theta$ values of calcinated $\mathrm{Fe}_{3} \mathrm{O}_{4}$ nano/microparticles were $30.0^{\circ}, 35.4^{\circ}$, and $37.4^{\circ}$, which corresponds to the Bragg reflections (220), (311), and (222), respectively (Table 2). By comparing the X-ray diffraction patterns prepared of $\mathrm{Fe}_{3} \mathrm{O}_{4}$ nano/microparticles with standard data, we concluded that the particles were mainly composed of $\mathrm{Fe}_{3} \mathrm{O}_{4}$ nano/microparticles [27, 28]. 
To determine the degree of oxidation of the $\mathrm{Fe}_{3} \mathrm{O}_{4}$ particles, TGA analysis was performed, and the result is shown in Figure 3(c), curve 1. When the $\mathrm{Fe}_{3} \mathrm{O}_{4}$ particles were heated in air up to $750^{\circ} \mathrm{C}$ at $10^{\circ} \mathrm{C} \mathrm{min}{ }^{-1}$, a significant weight loss was observed, which can be attributed to the oxidation of the $\mathrm{Fe}_{3} \mathrm{O}_{4}$ core [19]. The thermal stability of $\mathrm{Fe}_{3} \mathrm{O}_{4}$ particles was investigated by TGA measurements. The black particles were observed to turn red upon test completion, a characteristic of $\mathrm{Fe}_{3} \mathrm{O}_{4}$ rather than black carbon, indicating the complete loss of pyrrole. The weight loss at temperatures lower than $592.56^{\circ} \mathrm{C}$ is due to loss of moisture, while the major loss at temperatures higher than $700.39^{\circ} \mathrm{C}$ is due to the decomposition of pyrrole. The difference in the residue reflects the different amount of $\mathrm{Fe}_{3} \mathrm{O}_{4}$ particles present. The thermal stability increases slightly with increasing particles loading, which is believed to be due to both the lower mobility of the polymer chains when the polymer chains are bound to the particles and stronger chemical interaction [19]. Figure 3(c) curve 2-represents differential thermogram analysis (DTA) of $\mathrm{Fe}_{3} \mathrm{O}_{4}$ particles from this figure, it is clear that endothermic reaction takes place. The first broad peak was observed at $77.77^{\circ} \mathrm{C}$ and; a second at $647.40^{\circ} \mathrm{C}$ due to the decomposition of pyrrole and the possible phase transition of $\mathrm{Fe}_{3} \mathrm{O}_{4}$, respectively. As compared with no obvious phase transition in the pure $\mathrm{Fe}_{3} \mathrm{O}_{4}$ particles, the observed phase transition is likely due to an intermediate product of pyrrole. This cheap method of $\mathrm{Fe}_{3} \mathrm{O}_{4}$ synthesis is scalable and can be exploited for various applications such as MRI contrast enhancement, catalyst for carbon nanotubes growth and, is currently being pursued.

\section{Conclusion}

We synthesized $\mathrm{Fe}_{3} \mathrm{O}_{4}$ rod-shaped nano/microparticles by chemical reduction of $\mathrm{Fe}^{3+}$ ions using $\mathrm{NaBH}_{4}$ reducing agent and pyrrole as a surfactant. The $\mathrm{X}$-ray diffraction pattern concluded that the particles are mainly composed of $\mathrm{Fe}_{3} \mathrm{O}_{4}$ crystals. The SEM images confirm rod shape of $\mathrm{Fe}_{3} \mathrm{O}_{4}$ particles. The average aspect ratio of the stated particles was $\sim 2.8$. TGA analysis revealed that the surfaces of particles were oxidized containing about $5 \%$ weight loss of iron oxide. The FTIR spectra of $\mathrm{Fe}_{3} \mathrm{O}_{4}$ rod-shaped particles clearly indicated that the particles were coated by dispersing agent pyrrole. The colloidal solution of $\mathrm{Fe}_{3} \mathrm{O}_{4}$ particles exhibited magnetic properties. This synthesis route is economical and convenient method to fabricate $\mathrm{Fe}_{3} \mathrm{O}_{4}$ particles, which could be suitable for various applications such as MRI contrast enhancement, biodiseperations, $\mathrm{Ni}-\mathrm{Fe}$ batteries, and as a catalyst.

\section{Acknowledgment}

A. Thorat acknowledges the head Department of Chemistry of University of Pune for financial support.

\section{References}

[1] M. A. Zalich, M. L. Vadala, J. S. Riffle, M. Saunders, and T. G. S. Pierre, "Structural and magnetic properties of cobalt nanoparticles encased in siliceous shells," Chemistry of Materials, vol. 19, no. 26, pp. 6597-6604, 2007.
[2] C. Pascal, J. L. Pascal, F. Favier, M. L. E. Moubtassim, and C. Payen, "Electrochemical synthesis for the control of $\gamma-\mathrm{Fe}_{2} \mathrm{O}_{3}$ nanoparticle size, morphology, microstructure, and magnetic behavior," Chemistry of Materials, vol. 11, p. 141, 1999.

[3] H. Lee, E. Lee, D. K. Kim, N. K. Jang, Y. Y. Jeong, and S. Jon, "Antibiofouling polymer-coated superparamagnetic iron oxide nanoparticles as potential magnetic resonance contrast agents for in vivo cancer imaging," Journal of the American Chemical Society, vol. 128, no. 22, pp. 7383-7389, 2006.

[4] C. Alexiou, R. J. Schmid, R. Jurgons et al., "Targeting cancer cells: magnetic nanoparticles as drug carriers," European Biophysics Journal, vol. 35, no. 5, pp. 446-450, 2006.

[5] P. A. Dresco, V. S. Zaitsev, R. J. Gambino, and B. Chu, "Preparation and properties of magnetite and polymer magnetite nanoparticles," Langmuir, vol. 15, no. 6, pp. 1945-1951, 1999.

[6] H. Deng, X. Li, Q. Peng, X. Wang, J. Chen, and Y. Li, "Monodisperse magnetic single-crystal ferrite microspheres," Angewandte Chemie International Edition, vol. 44, no. 18, pp. 2782-2785, 2005.

[7] D. Beydoun, R. Amal, G. K. C. Low, and S. McEvoy, "Novel photocatalyst: titania-coated magnetite. Activity and photodissolution," Journal of Physical Chemistry B, vol. 104, no. 18, pp. 4387-4396, 2000.

[8] W. Stahlhofen and W. Moller, "Behaviour of magnetic microparticles in the human lung," Radiation and Environmental Biophysics, vol. 32, pp. 221-238, 1993.

[9] W. Möller, S. Takenaka, M. Rust, W. Stahlhofen, and J. Heyder, "Probing mechanical properties of living cells by magnetopneumography," Journal of Aerosol Medicine, vol. 10, no. 3, pp. 173-186, 1997.

[10] H. E. Stokinger, "A review of world literature finds iron oxides noncarcinogenic," American Industrial Hygiene Association Journal, vol. 45, no. 2, pp. 127-133, 1984.

[11] D. Cohen, "Ferromagnetic contamination in the lungs and other organs of the human body," Science, vol. 180, no. 4087, pp. 745-748, 1973.

[12] T. Sugimoto and E. Matijević, "Formation of uniform spherical magnetite particles by crystallization from ferrous hydroxide gels," Journal of Colloid and Interface Science, vol. 74, no. 1, pp. 227-243, 1980.

[13] W. Stahlhofen, J. Gebhart, J. Heyder, and B. Stuck, "Production of monodisperse $\mathrm{Fe}_{2} \mathrm{O}_{3}$ aerosols as test standards with a "spinning top" generator," Staub, Reinhaltung der Luft, vol. 39, no. 3, pp. 73-77, 1979.

[14] K. T. Wu, Y. D. Yao, C. R. C. Wang, P. F. Chen, and E. T. Yeh, "Magnetic field induced optical transmission study in an iron nanoparticle ferrofluid," Journal of Applied Physics, vol. 85, no. 8, pp. 5959-5961, 1999.

[15] D. Zhang, Z. Tong, S. Li, X. Zhang, and A. Ying, "Fabrication and characterization of hollow $\mathrm{Fe}_{3} \mathrm{O}_{4}$ nanospheres in a microemulsion," Materials Letters, vol. 62, no. 24, pp. 4053-4055, 2008.

[16] Y. W. Jun, Y. M. Huh, J. S. Choi et al., "Nanoscale size effect of magnetic nanocrystals and their utilisation for cancer diagnosis via magnetic resonance imaging," Journal of the American Chemical Society, vol. 127, no. 16, pp. 5732-5733, 2005.

[17] A. Nomura, S. Shin, O. O. Mehdi, and J. M. Kauffmann, "Preparation, characterization, and application of an enzymeimmobilized magnetic microreactor for flow injection analysis," Analytical Chemistry, vol. 76, no. 18, pp. 5498-5502, 2004.

[18] F. Li, C. Vipulanandan, and K. K. Mohanty, "Microemulsion and solution approaches to nanoparticle iron production for 
degradation of trichloroethylene," Colloids and Surfaces A, vol. 223, no. 1-3, pp. 103-112, 2003.

[19] C. Yang, J. Xing, Y. Guan, J. Liu, and H. Liu, "Synthesis and characterization of superparamagnetic iron nanocomposites by hydrazine reduction," Journal of Alloys and Compounds, vol. 385, no. 1-2, pp. 283-287, 2004.

[20] W.-X. Zhang, "Nanoscale iron particles for environmental remediation: an overview," Journal of Nanoparticle Research, vol. 5, no. 3-4, pp. 323-332, 2003.

[21] K. C. Huang and S. H. Ehrman, "Synthesis of iron nanoparticles via chemical reduction with palladium ion seeds," Langmuir, vol. 23, no. 3, pp. 1419-1426, 2007.

[22] A. Chen, H. Wang, B. Zhao, and X. Li, "The preparation of polypyrrole- $\mathrm{Fe}_{3} \mathrm{O}_{4}$ nanocomposites by the use of common ion effect," Synthetic Metals, vol. 139, no. 2, pp. 411-415, 2003.

[23] B. Zhao and Z. Nan, "Preparation of stable magnetic nanofluids containing $\mathrm{Fe}_{3} \mathrm{O}_{4} @ P P y$ nanoparticles by a novel one-pot route," Nanoscale Research Letters, vol. 6, Article ID 230, pp. 1-8, 2011.

[24] Y. R. Sharma, Elementary Organic Spectroscopy: Principles and Chemical Applications, S. Chand \& Co., 4th edition, 2012.

[25] C. T. Seip and C. J. O’Connor, "Fabrication and organization of self-assembled metallic nanoparticles formed in reverse micelles," Nanostructured Materials, vol. 12, no. 1, pp. 183-186, 1999.

[26] G. N. Glavee, K. J. Klabunde, C. M. Sorensen, and G. C. Hadjipanayis, "Chemistry of borohydride reduction of Iron (II) and Iron (III) ions in aqueous and non-aqueous media. Formation of nanoscale $\mathrm{FeB}, \mathrm{Fe}_{2} \mathrm{~B}$ and other iron-rich boride powders," Inorganic Chemistry, vol. 34, pp. 28-35, 1995.

[27] X. Lu, H. Mao, and W. Zhang, "Fabrication of core-shell $\mathrm{Fe}_{3} \mathrm{O}_{4}$ /polypyrrole and hollow polypyrrole microspheres," Polymer Composites, vol. 30, no. 6, pp. 847-854, 2009.

[28] B. Ankamwar, T. C. Lai, J. H. Huang et al., "Biocompatibility of $\mathrm{Fe}_{3} \mathrm{O}_{4}$ nanoparticles evaluated by in vitro cytotoxicity assays using normal, glia and breast cancer cells," Nanotechnology, vol. 21, no. 7, Article ID 75102, 2010. 

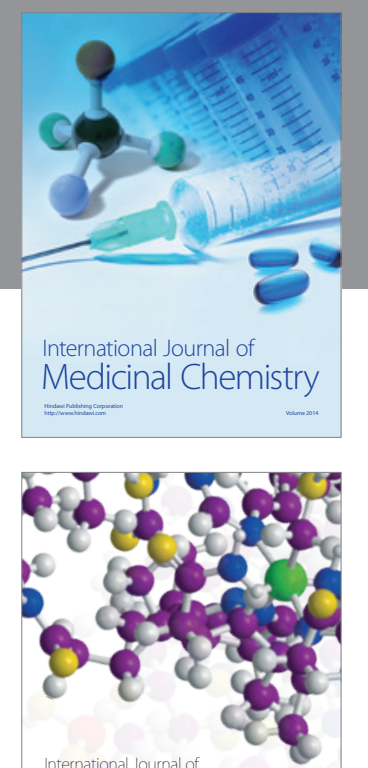

\section{Carbohydrate} Chemistry

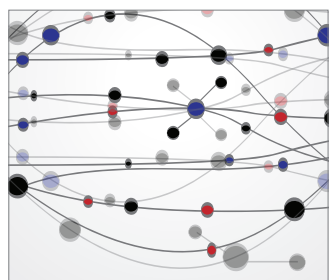

The Scientific World Journal
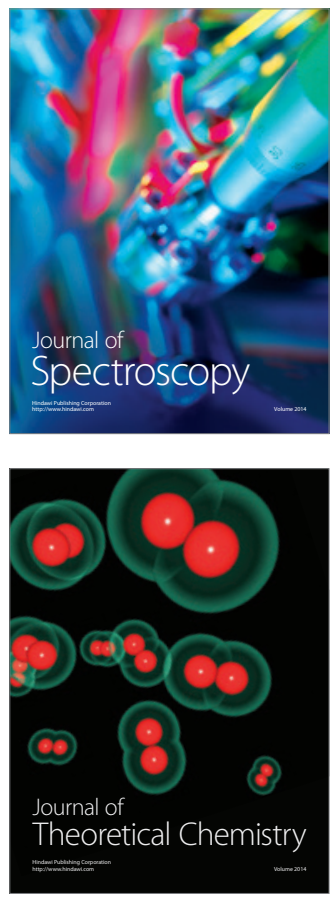
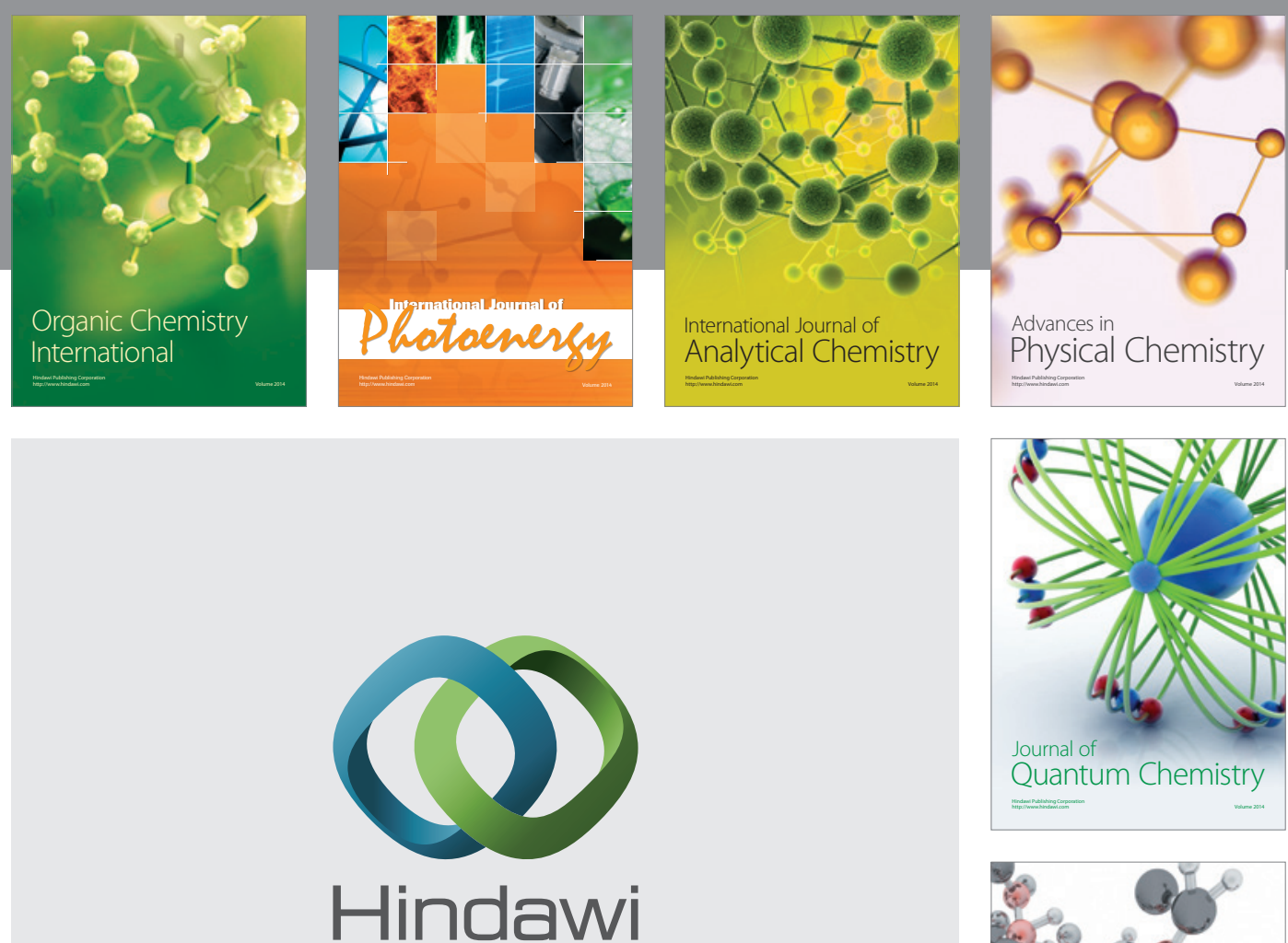

Submit your manuscripts at

http://www.hindawi.com

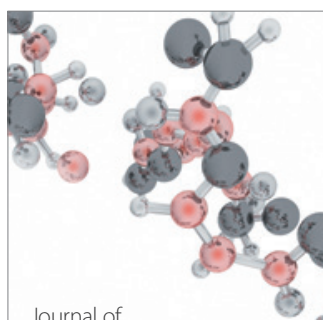

Analytical Methods

in Chemistry

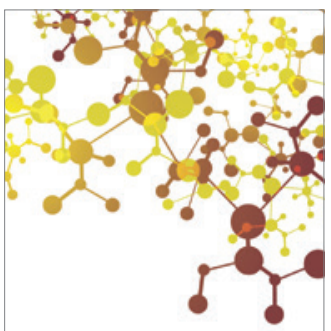

Journal of

Applied Chemistry

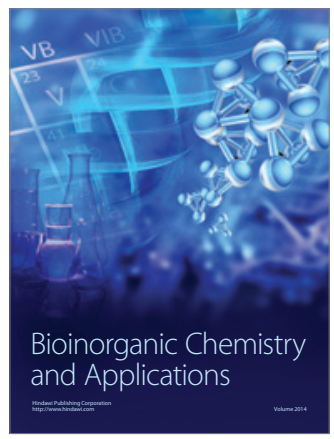

Inorganic Chemistry
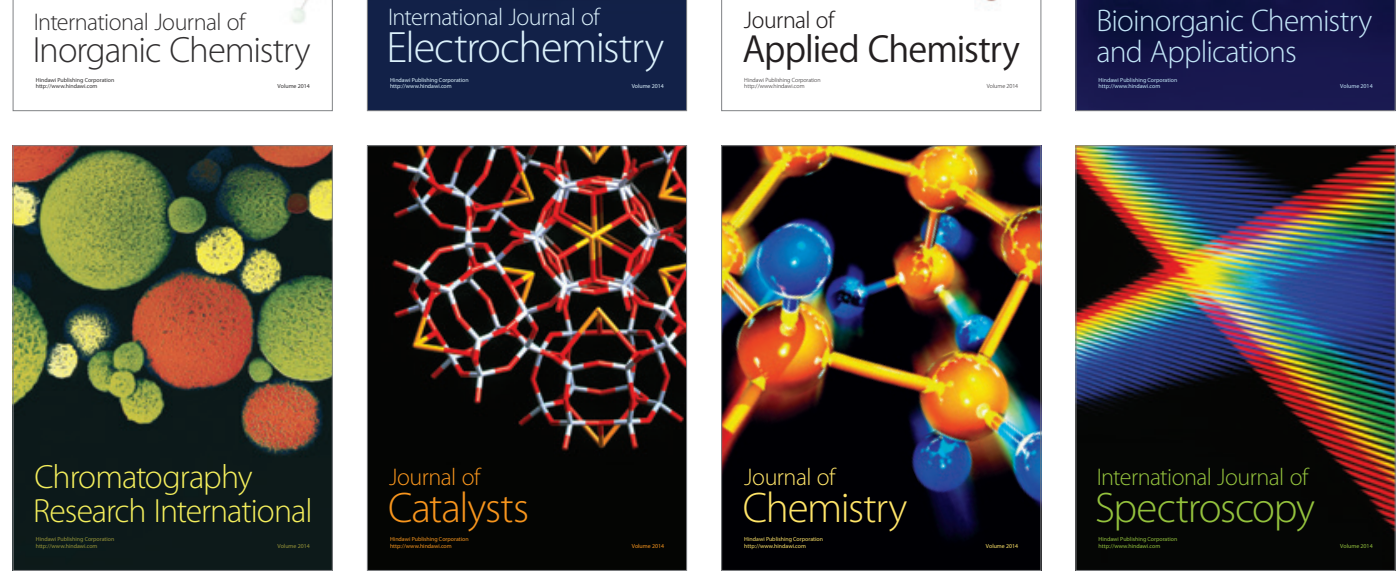